\title{
Combining abilities analysis for ear rot resistance in popcorn hybrids development
}

\author{
Rafael Nunes de Almeida ${ }^{1 *}\left(\mathbb{D}\right.$, Marcelo Vivas $^{1}$, Divino Rosa dos Santos Junior ${ }^{l}$, Júlio Cesar Gradice Saluci ${ }^{1}$, \\ Mayara Cazadini Carlos ${ }^{1}$, Juliana Saltires Santos ${ }^{1}$, Antônio Teixeira do Amaral Júnior ${ }^{1}$, Carlos Alberto Scapim ${ }^{2}$
}

\author{
$10.1590 / 0034-737 X 202168010008$
}

\begin{abstract}
Ear rot caused by fungi of genus Fusarium (FER) is one of the potentially harmful diseases to grain quality in maize. Given the capacity to produce mycotoxins, FER presents a risk to food safety. This study sought to identify parents and indicate hybrids of popcorn with a higher level of resistance to the incidence and severity of FER. Hybrids were produced from the crossing of 15 lines in S7 generation and 5 testers. The hybrids, together with the parents and five more genotypes used as control, were evaluated in a field trial. It was used a randomized block design arranged in 10 $\mathrm{x} 10$ lattice. Data were submitted to analysis of variance by the $\mathrm{F}$ test $(\mathrm{p}<0.05)$ and then by the mean grouping test of Scott Knott $(\mathrm{p}<0.05)$. The results showed the possible to explore new sources of resistance to FER among germplasm evaluated. Both additive and non-additive gene effects are important in FER resistance. To obtain gains in FER resistance, the development of popcorn hybrids should consider the use of parental lines with low means of severity and good general combining ability.
\end{abstract}

Keywords: resistance to disease; food safety; combining ability; genetic resources; plant breeding.

\section{INTRODUCTION}

Ear rot caused by Fusarium spp. (FER) is a harmful disease for maize cultivation, with the possibility of reducing the average grain yield by between 10 and $30 \%$ (Logrieco et al., 2002). Besides losses in grain quality, another source of concern is the mycotoxin production (fumonisins), which have been associated with the development of liver diseases in humans, and heart failure and neural paralysis in domestic animals (Ross et al., 1990; Missmer et al., 2006).

Growing more resistant varieties to Fusarium spp. infection has been one of the strategies to reduce ear rot and, consequently, the accumulation of mycotoxins in grains (Horne et al., 2016; Santiago et al., 2020). Given that food safety is put at risk by the accumulation of mycotoxins in grains, a factor that tends to worsen with the climate change scenario predicted for years to come (Medina et al., 2017), the development and cultivation of plants resistant to FER may contribute to the maintenance of food safety.

Accordingly, efforts have been made worldwide to develop common maize cultivars with a higher level of resistance to rot (Han et al., 2016; Nerbass et al., 2016; Jindal et al., 2019). When the focus is on special maize, however, especially for popcorn, it is observed studies are less frequent. Even though concerns about food safety are greater for common maize, some countries have regulated minimum quality standards for the commercialization of popcorn grains regarding the accumulation of mycotoxins (Anvisa, 2011), thereby proving that increasing phytosanitary quality is also a challenge for popcorn producers.

Submitted on April 15 $5^{\text {th }}, 2020$ and accepted on October $18^{\text {th }}, 2020$.

${ }^{1}$ Universidade Estadual do Norte Fluminense Darcy Ribeiro, Campos dos Goytacazes, Rio de Janeiro, Brazil. mrclvivas@hotmail.com; juniorifagro@gmail.com; juliosaluci@gmail.com; may_cazadini@hotmail.com; julianasaltiresdossantos@yahoo.com.br; amaraluenf@gmail.com.

${ }^{2}$ Universidade Estadual de Maringá, Maringá, Paraná, Brazil. cascapim@uem.br.

*Corresponding author: almeida.rna94@gmail.com 
For developing maize cultivars resistant to FER, the investigation of simple hybrids from the cross of lines pre-evaluated as superior has been pointed out as promising, both for common maize and for popcorn (Lanubile et al., 2017; Gabriel et al., 2018). To obtain hybrids, different breeding strategies can be implemented, with genetic designs in diallel and testcrosses being frequently adopted. The use of complete diallel has proven to be efficient for the exploration of popcorn hybrids, and for the identification of promising parents for breeding programs (Schwantes et al., 2017). However, the use of this genetic design is limited when the focus is on working with a larger number of parents, since it makes the process of evaluating progeny laborious and costly. The use of partial diallel has been adopted as an option for the evaluation of a greater number of parents in hybrid crosses in common maize, allowing estimating the general and specific combining ability of these parents and hybrids, in a less onerous way to breeding programs.

It is believed that among collections of tropical germplasm, there are populations that are sources of alleles to FER resistance but, the genetic prospection of them alleles are only beginning in tropical regions. For example, the use of partial diallel for crosses in popcorn, with the goal of FER resistance was not found in the scientific literature. As such, with the identification of lines carrying resistance alleles, it is recognized that it is possible both to obtain more resistant popcorn hybrids and to contribute to the advancement of popcorn breeding programs in tropical regions by making available genotypes resistant to rot.

Due the high susceptibility to FER on commercial cultivars, the breeders have been worked to obtain varieties and hybrids with more level of genetic resistant cultivars (Horne et al., 2016; Gabriel et al., 2018; Santiago et al., 2020). These aspects revel an urgency on the identification of new sources of rot resistance to contribute in reduction of agrochemicals demands and improve the phytosanitary quality on maize grains.

From the hypothesis that the development of hybrids is a promising strategy both in identification of new sources to FER genetic resistance and to reduce the severity of disease on cultivars, the study aimed to evaluate the combining ability of popcorn lines and to select hybrids for Fusarium ear rot resistance from partial diallel crosses.

\section{MATERIALS AND METHODS}

The hybrids were obtained by crossing lines from the UENF 14 population with different testers (Table 1), were evaluated with the purpose to obtain superior hybrids for disease resistance and of exploring potential parents for future crosses.
The UENF 14 population is the result of intrapopulation recurrent selection from the UNB2 population (Amaral Júnior et al., 2013). The inbred lines used in this study were obtained from successive selffertilizations of hundreds of plants in UENF 14 population starting in 2012. Selections were made along the process for greater yield and popping expansion, resulting in a little more than ten lines in S7 stage.

Concerning the testers utilized, four of them are characterized as of narrow genetic base: L270, P1, L70, and L651; and the other, of broad genetic base: PARA 172 population. The choice of a broad-based tester was due to the fact that this type of tester serves as a basis to better infer the general combining ability of female parents (Miranda Filho, 2018). Moreover, the PARA 172 population (CIMMYTMA 4157 access) refers to an open-pollinated population, which is pointed as a source of alleles of resistance to ear rot (Solalinde et al., 2014).

For narrow-base testers, line L651 is derived from the ARZM 13050 population of a local breed from Argentina. This population is described in the Cimmyt database as moderately resistant to ear rot (Cimmyt, 2019). The L70 line originates from the BRS Angela population, developed by Embrapa Milho e Sorgo (Embrapa Maize and Sorghum) from a recurrent selection in the CMS 43 population, with the goal of increasing the expansion ability. The BRS Angela population was identified as promising for various agronomic attributes, including resistance to multiple leaf diseases (Pacheco et al., 2001). The P1 tester is derived from commercial hybrids obtained by crossing national varieties and commercial hybrids from the United States. The L270 tester comes from the PARA 172 population.

The 75 hybrids obtained, together with the parents and the following five controls: L51, L88 lines, ARZM 13050 and UFV-M2 Barão de Viçosa populations, and the UENF HSO2 cultivar, registered by Universidade Estadual do Norte Fluminense Darcy Ribeiro (UENF) in 2017, composed the field trial with a total of 100 genotypes (treatments). Kurosawa et al. (2017) and Schwantes et al. (2017) classified ARZM 13050 and UFV-M2 Barão de Viçosa populations, and L51 and L88 lines as susceptible to ear rot (Kurosawa et al., 2017; Schwantes et al., 2017). The UENF HS02 cultivar was used as a control because of its good performance for yield and popping expansion, thereby enabling to verify the potential of this hybrid also for rot resistance.

The field trial was installed at Colégio Agrícola Antônio Sarlo, in the municipality of Campos dos Goytacazes, state of Rio de Janeiro, Brazil, between April and July 2018. Treatments were arranged following an incomplete block design with three replicates, placed in 10x10 lattice, totalling 300 experimental units. Each experimental unit was composed of 25 plants, spacing 0.20 
$\mathrm{m}$ between plants $\mathrm{x} 0.90 \mathrm{~m}$ between rows, resulting in an approximate density of 55,000 plants ha- ${ }^{-1}$.

The average daily temperature and the accumulated daily rainfall volume (Figure 1) were measured by a weather station installed 100 meters from the planting area.

After the ears were harvested and unhusked, the incidence (IFER) and severity (SFER) of Fusarium ear rot were evaluated. Although the evaluations have been conducted in only one environment, the results have a good level of reliability because the heritability for this trait is commonly high (Robertson et al., 2006; Löffler $e t$ al., 2011; Pereira et al., 2017).
The mean percentage of IFER was calculated from the ratio between the number of ears infected by Fusarium and the total number of ears produced per plot, whereas SFER was determined from the mean percentage of visibly infected grains in each one of the affected ears. The evaluation of SFER was carried out by visual analysis, following the diagrammatic scale proposed by Cimmyt (1985).

Data were tabulated in electronic spreadsheets for subsequent analysis. It was verified the variance between treatments by the $\mathrm{F}$ test $(\mathrm{p}<0.05)$ according to the statistical model:

Table 1: Description of popcorn lines as to the response to the incidence and severity of Fusarium ear rot

\begin{tabular}{llll}
\hline & \multicolumn{1}{c}{ Type } & Genealogy & FER Resistance * \\
\hline Male Parents & & & Suscetible \\
\hline L270 & Inbred Line $\left(\mathrm{S}_{7}\right)$ & PARA 172 & Moderate \\
P1 & Inbred Line $\left(\mathrm{S}_{7}\right)$ & Hybrid Zélia & Resistant \\
PARA 172 & Population & Paraguai/CIMMYT & Resistant \\
L70 & Inbred Line $\left(\mathrm{S}_{7}\right)$ & Ângela EMPRAPA & Moderate \\
L651 & Inbred Line $\left(\mathrm{S}_{7}\right)$ & ARZM 13050 & \\
\hline Female Parents & & & Unknow \\
\hline L204 & & IAC 125 & Unknow \\
L681 & Inbred Line $\left(\mathrm{S}_{7}\right)$ & UENF 14 & Unknow \\
L682 & Inbred Line $\left(\mathrm{S}_{7}\right)$ & UENF 14 & Unknow \\
L683 & Inbred Line $\left(\mathrm{S}_{7}\right)$ & UENF 14 & Unknow \\
L684 & Inbred Line $\left(\mathrm{S}_{7}\right)$ & UENF 14 & Unknow \\
L685 & Inbred Line $\left(\mathrm{S}_{7}\right)$ & UENF 14 & Unknow \\
L686 & Inbred Line $\left(\mathrm{S}_{7}\right)$ & UENF 14 & Unknow \\
L688 & Inbred Line $\left(\mathrm{S}_{7}\right)$ & UENF 14 & Unknow \\
L689 & Inbred Line $\left(\mathrm{S}_{7}\right)$ & UENF 14 & Unknow \\
L691 & Inbred Line $\left(\mathrm{S}_{7}\right)$ & UENF 14 & Unknow \\
L692 & Inbred Line $\left(\mathrm{S}_{7}\right)$ & UENF 14 & Unknow \\
L693 & Inbred Line $\left(\mathrm{S}_{7}\right)$ & UENF 14 & Unknow \\
L694 & Inbred Line $\left(\mathrm{S}_{7}\right)$ & UENF 14 & Unknow \\
L695 & Inbred Line $\left(\mathrm{S}_{7}\right)$ & UENF 14 & Unknow \\
L696 & Inbred Line $\left(\mathrm{S}_{7}\right)$ & UENF 14 & \\
\hline
\end{tabular}

* Fusarium ear rot - FER

A

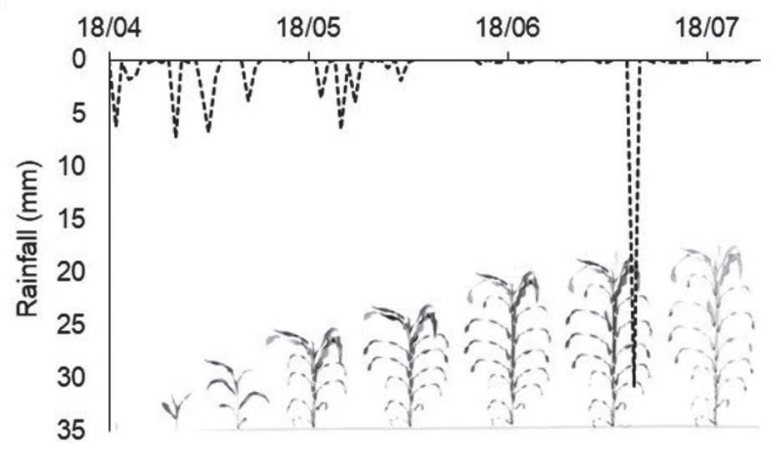

B

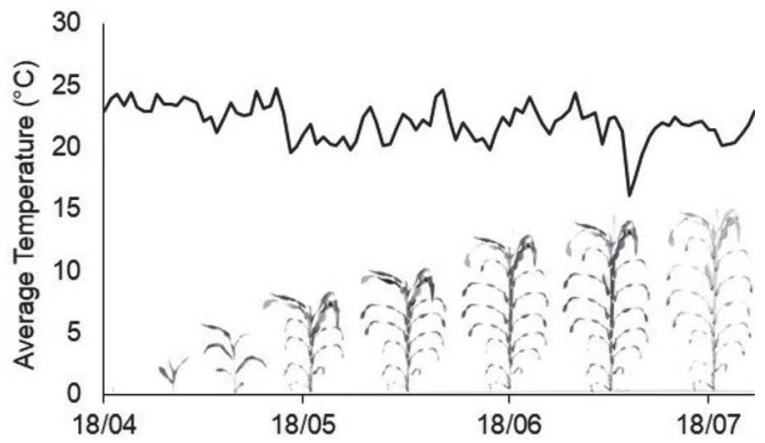

Figure 1: Total daily rainfall volume (dotted line - A) and average daily temperature (black line - B) in the municipality of Campos dos Goytacazes, state of Rio de Janeiro, Brazil, from April to July 2018. 
$\mathrm{Y}_{\mathrm{ijk}}=\mu+\mathrm{G}_{\mathrm{i}}+\mathrm{r}_{\mathrm{j}}+\mathrm{b}_{\mathrm{k}(\mathrm{j})}+\varepsilon_{\mathrm{ijk}}$

In which $\mathrm{Y}_{\mathrm{ijk}}$ is the value observed for treatment $\mathrm{i}$ in block $\mathrm{k}$, within the repetition $\mathrm{j} ; \mu$, a general constant for the character evaluated; $G_{i}$, the random effect of treatment $i$, being the distribution NID $(0, \sigma 2 G) ; r_{j}$ is the fixed effect of repetition $\mathrm{j}$; $b_{k(j)}$ the random effect of incomplete block $k$, with a rank inside the repetition $\mathrm{j}$, with distribution NID $(0$, $\sigma 2 \mathrm{~B})$; and $\mathrm{e}_{\mathrm{ijk}}$, the experimental error associated with observation $\mathrm{Y}_{\mathrm{ijk}}$ with distribution NID $(0, \sigma 2)$. After verifying the significant differences between genotypes, the Scott-Knott mean grouping test $(p<0.05)$ was conducted to identify parents and hybrids with lower levels of IFER and SFER.

Based on the adjusted means of treatments, the analysis of variance was conducted taking into account the mating design in partial diallel, according to the model proposed by Griffing (1956), adapted by Geraldi \& Miranda Filho (1988), with the statistical model as follows:

$Y_{i j}=\mu+\frac{1}{2}\left[d_{1}+d_{2}\right]+g_{i}+g_{j}+s_{i j}+\varepsilon_{i j}$

In which $\mathrm{Y}_{\mathrm{ij}}$ is the mean value of the combining hybrid between the $\mathrm{i}$-th tester of group 1 and the $\mathrm{j}$-th inbred line of group $2 ; \mu$ is the general constant for the character under evaluation; $d_{1}$ and $d_{2}$ are the effects of genotypes from group 1 (testers) and group 2 (lines), respectively; $\mathrm{g}_{\mathrm{i}}$ is the effect of the general combining ability of the i-th parent of group $1 ; \mathrm{g}_{\mathrm{j}}$ is the effect of the general combining ability of the $\mathrm{j}$-th parent of group $2 ; \mathrm{s}_{\mathrm{ij}}$ is the effect of the specific combining ability of hybrids formed of groups 1 and 2, respectively; and $\mathrm{e}_{\mathrm{ij}}$, the mean experimental error for each treatment.

We use the Genes software to conduct the analyses (Cruz, 2013).

\section{RESULTS}

The analysis of variance demonstrated significant effects of the genotypes, thereby suggesting the possibility of classifying hybrids with higher levels of resistance or susceptibility to IFER and SFER (Table 2).

Significant differences among lines prove there is a genetic variability among them, and this is essential to explore the effect of heterosis, thereby enabling the exploration of hybrids from these lines to obtain gains in resistance to IFER and SFER.

The mean heritability $\left(\mathrm{h}^{2}\right)$ for the characters indicated high influence of genetic effects on the phenotypic expression, also reflected in the index of genotypic variation, which indicated the predominance of variations by genotypic effects.

By analyzing the treatment means, it can be seen the IFER evaluation allowed distinguishing both parents and hybrids with lower number of affected ears (Table 3 ).
Given the 15 testcross hybrids from the crosses between the lines with the highest level of resistance (L683, L685, L691) and the corresponding testers, it was found the testers with the highest level of resistance also generated hybrids more resistant to IFER. For genotypes evaluated as controls, the susceptibility of L88 and L51 lines to IFER was corroborated.

The identifying sources of resistance is crucial not only to evaluate the incidence of the pathogen but also its severity (Lanubile et al., 2017). The analysis of data for SFER, as well as for incidence, allowed distinguishing parents and topcross hybrids in different groups according to the level of resistance to Fusarium (Table 3 ). L683, L689, L691, and L695 were the most prominent lines tested, with SFER ranging from $12.41 \%$ to $26.46 \%$. Among the testers, L70 line and PARA 172 population stood out from the others.

Only four out of the 75 testcrosses hybrids showed higher values for SFER, namely L204xL270, L204xP1, L681xL270, and L688xL270. Among the other 74 hybrids, the mean SFER ranged from $2.23 \%$ (L691xL551) to $22.99 \%$ (L689xL651). It was also seen that the crosses comprising the L70, L651, and PARA 172 testers generated hybrids with higher levels of resistance, irrespective of the level of resistance of the maternal parents. Likewise, crosses with L683, L689, L691, and L695 lines resulted in hybrids with lower SFER regardless of the level of resistance of the testers.

Because of the use of mating design in partial diallel, it was possible to analyse whether there were significant effects due to combining abilities (Table 4).

The analysis of variance for the topcross model proved there was a considerable difference among the parents; however, there was no significant difference for the effects of the general combining ability of the testers.

The GCA effects of IFER and SFER of the tested lines presented greater variation than the effects resulting from the SCA of hybrids (Tables 5). The difference was even greater for SFER.

With respect to the ability of parents to contribute to resistance to FER, the analysis of general combining ability (GCA) evidenced that only the L651 and P1 testers contributed to the reduction in IFER, and among them, only L651 contributed to the reduction in SFER. The Para 172 population, on the other hand, contributed to the reduction of both characters.

\section{DISCUSSION}

The existence of variance is a prerequisite to select higher individuals in breeding programs. In this sense, the exploration of genetic variability can be enhanced by increasing experimental precision so that genetic effects can be better distinguished from plant phenotype. 
Besides showing that there is a variance between the tested hybrids the analysis of the efficiency of the experimental design proposed point out the use of lattice was efficient for a greater local control, which resulted in experimental coefficients of variation with expected values. Some cases showed the coefficients obtained in this study were lower than the ones described in the literature, especially for the IFER variable (Flett et al., 1998; Gabriel et al., 2018; Mabuza et al., 2018).

In accordance with this information, the high heritability values suggest there is the possibility of obtaining real gains in genetic resistance to FER, from simple selection methodologies, without using many environments, for example (Cruz et al., 2014).

Our means test show that, in most hybrid combinations, the cross between two susceptible lines did not only result in hybrids that are more susceptible. This observation diverged from that of Hung \& Holland (2012), who, when evaluating common maize hybrids obtained in diallel crosses, identified that no hybrids with good levels of resistance were generated at any of the crosses between two parents with FER susceptibility. So, the results show that the non-additive effects are important in resistance genes expression and that consequently the advantage in the development of hybrids to reduce SFER.

Among the hybrids, we observed a high level of FER resistance. Others studies on resistance to ear rot in common maize have described hybrids with values lower than $10 \%$ of severity in ears as being highly resistant, when evaluating interpopulation hybrids of maize, it reported a percentage of $2.6 \%$ of SFER in the most resistant hybrids (Li et al., 2019; Galiæ et al., 2019). Czembor et al. (2019) described values of $1.3 \%$ to $4.3 \%$ of SFER in common maize populations, which were indicated as sources of resistance. When these values are considered as a reference, it can be noticed that 54 out of the 75 hybrids evaluated showed mean values lower than $10 \%$ of SFER, which can be regarded as highly resistant. It should also be noted that all crosses comprising the L70 and PARA 172 testers (testers with lower values per se of SFER) resulted in highly resistant hybrids.

However, these values of severity can be considered high. So, the utilization of lines with less value of SER and good combining ability can potentialize the gains in resistance.

Given the relationship between the percentages of IFER and SFER, emphasis is given to the L691xL651 hybrid, in which about $41.72 \%$ of the ears presented IFER, with a mean SFER of $2.23 \%$ of their infected grains (Tables 3). This means the estimated loss of grains as a result of the occurrence of Fusarium was about $0.9 \%$ of the total produced in the plots planted with this hybrid (value doesn't consider other losses, how in the harvest for example). The same value can be estimated for the L691 x PARA 172 hybrid; however, since it is a cross between a line and a test population, it is less interesting from a commercial point of view than the L691 x L651 hybrid.

For both IFER and SFER, it was observed that the averages of the hybrids were lower than the parents. This evidenced both the effect of inbreeding in the lines and the effect of the exploration of heterosis for resistance to ear rot in popcorn hybrids. As such, results confirm the consensus that, similarly to common maize, the prospection of lines and generation of hybrids in popcorn has been, so far, a promising method to obtain gains in resistance to ear rot (Lanubile et al., 2017; Schwantes et al., 2017).

Table 2: Variance analysis to incidence (IFER) and severity (SFER) of Fusarium ear rot in testcross popcorn hybrids

\begin{tabular}{lccc}
\hline \multirow{S}{*}{} & df & \multicolumn{2}{c}{ MS } \\
\cline { 2 - 3 } & & ${ }^{\dagger}$ IFER & ${ }^{\ddagger}$ SFER \\
\hline Repetition (Rep) & 2 & 3653.60 & 187.31 \\
Block/Rep (Adjusted) & 27 & 711.09 & 417.28 \\
Genotype (Adjusted) & 99 & $849.37 * *$ & $781.98 * *$ \\
Error & 171 & 131.15 & 101.36 \\
\hline Total & 299 & & 134.20 \\
\hline Lattice efficiency & & 151.48 & 226.87 \\
$\sigma^{2}{ }^{g}$ & & 239.41 & 260.66 \\
$\sigma^{2}$ & & 283.12 & 0.87 \\
$\mathrm{~h}^{2}$ & & 0.84 & 61.50 \\
$\mathrm{CVe}(\%)$ & 16.98 & 92.02 \\
$\mathrm{CVg}$ & & 22.94 & 1.49 \\
$\mathrm{CVg} / \mathrm{CVe}$ & & 1.35 & \\
\hline
\end{tabular}

$* * \mathrm{p}<0.01$; † Incidence of Fusarium ear rot (IFER); ${ }^{\ddagger}$ Severity of Fusarium ear rot (SFER); SV- source of variation; df - degree freedom; MS - mean square; $\sigma_{g}^{2}=$ genotypic variance; $\sigma_{\mathrm{f}}^{2}=$ phenotypic variance; $\mathrm{h}^{2}=$ heritability; CVe = environmental coefficient of variation; CVg = genotypic coefficient of variation. 
These genotypes (parental lines and hybrids) have a potential for use in several breeding programs from tropical regions. So, studies about the genotypes that has a better adaptation to each microregion is necessary to potentialize the gains in resistance.
Besides the means analysis, studies on combining ability of parents are relevant for planning future crosses to obtain even higher gains in resistance (Sprague et al., 1942). Our study shows that the differences among hybrids with common parental prove that knowing about

Table 3: Grouping of means for the IFER and SFER of ears affected by rot in lines and hybrids of popcorn

\begin{tabular}{|c|c|c|c|c|c|c|}
\hline \multicolumn{7}{|c|}{ Incidence Fusarium Ear Rot (IFER) } \\
\hline \multirow{3}{*}{ Inbred Lines } & & L270 & P1 & L70 & L651 & PARA 172 \\
\hline & & $88.99^{\mathrm{b}}$ & $78.79^{\mathrm{c}}$ & $83.46^{\mathrm{b}}$ & $78.41^{\mathrm{b}}$ & $81.73^{\mathrm{b}}$ \\
\hline & & Hybrids & & & & \\
\hline L204 & $97.22^{a}$ & $87.46^{\mathrm{a}}$ & $81.74^{b}$ & $60.09^{c}$ & $52.41^{\mathrm{d}}$ & $49.75^{\mathrm{d}}$ \\
\hline L681 & $81.81^{\text {b }}$ & $89.81^{\text {a }}$ & $63.54^{\mathrm{c}}$ & $67.98^{b}$ & $73.06^{\mathrm{b}}$ & $59.36^{\mathrm{c}}$ \\
\hline L682 & $91.88^{\mathrm{a}}$ & $54.43^{\mathrm{d}}$ & $58.26^{\mathrm{c}}$ & $62.07^{\mathrm{c}}$ & $60.97^{\mathrm{c}}$ & $60.26^{\mathrm{c}}$ \\
\hline L683 & $69.30^{\mathrm{c}}$ & $49.46^{\mathrm{d}}$ & $54.76^{\mathrm{c}}$ & $56.48^{\mathrm{c}}$ & $59.51^{\mathrm{c}}$ & $40.52^{\mathrm{d}}$ \\
\hline L684 & 96.67 a & $62.92^{c}$ & $58.82^{\mathrm{c}}$ & $45.73 \mathrm{~d}$ & $72.88^{b}$ & $61.54^{\mathrm{c}}$ \\
\hline L685 & $71.76^{\mathrm{c}}$ & $66.76^{\mathrm{c}}$ & $62.97^{\mathrm{c}}$ & $69.78^{\mathrm{b}}$ & $68.89^{c}$ & $49.08^{d}$ \\
\hline L686 & $96.67^{\mathrm{a}}$ & $57.85^{c}$ & $79.03^{b}$ & $66.81^{\mathrm{b}}$ & $85.23^{\mathrm{a}}$ & $62.35^{\mathrm{c}}$ \\
\hline L688 & $98.72^{a}$ & $52.96^{d}$ & $47.57^{\mathrm{d}}$ & $66.81^{\mathrm{b}}$ & $56.94^{d}$ & $59.84^{\mathrm{c}}$ \\
\hline L689 & $76.89^{b}$ & $65.51^{\mathrm{c}}$ & $73.66^{b}$ & $68.10^{\mathrm{c}}$ & $66.88^{c}$ & $58.25^{\mathrm{c}}$ \\
\hline L691 & $63.25^{\mathrm{c}}$ & $52.90^{\mathrm{d}}$ & $36.14^{\mathrm{d}}$ & $54.42^{c}$ & $41.72^{\mathrm{d}}$ & $35.73^{d}$ \\
\hline L692 & $91.67^{\mathrm{a}}$ & $62.61^{\mathrm{c}}$ & $92.12^{\mathrm{a}}$ & $64.53^{c}$ & $70.99^{\mathrm{c}}$ & $55.04^{\mathrm{d}}$ \\
\hline L693 & $80.67^{\mathrm{b}}$ & $74.57^{\mathrm{b}}$ & $63.08^{c}$ & $59.72^{c}$ & $60.34^{\mathrm{c}}$ & $59.95^{\mathrm{d}}$ \\
\hline L694 & $81.83^{a}$ & $62.70^{c}$ & $69.53^{c}$ & $50.27^{\mathrm{d}}$ & $65.35^{c}$ & $68.85^{\mathrm{b}}$ \\
\hline L695 & $89.18^{b}$ & $53.37^{\mathrm{c}}$ & $62.87^{c}$ & $74.07^{\mathrm{b}}$ & $78.79^{b}$ & $54.16^{\mathrm{d}}$ \\
\hline L696 & $84.82^{\text {b }}$ & $41.26^{\mathrm{d}}$ & $61.48^{c}$ & $53.49^{\mathrm{d}}$ & $71.09^{\mathrm{b}}$ & $47.96^{\mathrm{d}}$ \\
\hline \multicolumn{7}{|c|}{ Control Genotypes } \\
\hline UENF HS02 & & $62.32^{c}$ & & L88 & $96.29^{a}$ & \\
\hline ARZM 13050 & & $94.57^{\text {a }}$ & & L51 & $100.0^{\mathrm{a}}$ & \\
\hline Barão de Viçosa & & $82.78^{c}$ & & & & \\
\hline \multicolumn{7}{|c|}{ Severity to Fusarium Ear Rot (SFER) } \\
\hline \multirow{3}{*}{\multicolumn{2}{|c|}{ Inbred Lines }} & L270 & P1 & L70 & L651 & PARA 172 \\
\hline & & $47.28^{\mathrm{a}}$ & $38.25^{\mathrm{b}}$ & $20.86^{c}$ & $35.62^{b}$ & $15.98^{c}$ \\
\hline & & Hybrids & & & & \\
\hline L204 & $53.33^{\mathrm{a}}$ & $29.10^{b}$ & $29.51^{b}$ & $8.60^{c}$ & $7.12^{c}$ & $5.88^{\mathrm{c}}$ \\
\hline L681 & $51.50^{\mathrm{a}}$ & $29.25^{b}$ & $20.02^{c}$ & $6.96^{\mathrm{c}}$ & $11.84^{\mathrm{c}}$ & $9.45^{\mathrm{c}}$ \\
\hline L682 & $37.23^{b}$ & $5.49^{\mathrm{c}}$ & $4.50^{\mathrm{c}}$ & $8.15^{\mathrm{c}}$ & $4.20^{\mathrm{c}}$ & $4.46^{\mathrm{c}}$ \\
\hline L683 & $15.73^{c}$ & $4.87^{\mathrm{c}}$ & $9.05^{\mathrm{c}}$ & $3.45^{\mathrm{c}}$ & $5.12^{\mathrm{c}}$ & $3.56^{\mathrm{c}}$ \\
\hline L684 & $63.54^{\mathrm{a}}$ & $17.15^{\mathrm{c}}$ & $17.35^{\mathrm{c}}$ & $3.72^{\mathrm{c}}$ & $17.54^{\mathrm{c}}$ & $8.09^{c}$ \\
\hline L685 & $24.49^{b}$ & $10.99^{c}$ & $6.67^{\mathrm{c}}$ & $5,97^{\mathrm{c}}$ & $6.38^{c}$ & $2.84^{\mathrm{c}}$ \\
\hline L686 & $32.53^{\mathrm{b}}$ & $8.68^{c}$ & $19.06^{\mathrm{c}}$ & $6.84^{\mathrm{c}}$ & $15.90^{\mathrm{c}}$ & $8.86^{\mathrm{c}}$ \\
\hline L688 & $59.34^{a}$ & $25.56^{b}$ & $5.03^{\mathrm{c}}$ & $3.99^{\mathrm{c}}$ & $6.18^{c}$ & $7.04^{\mathrm{c}}$ \\
\hline L689 & $22.34^{\mathrm{c}}$ & $7.94^{\mathrm{c}}$ & $9.79^{\mathrm{c}}$ & $5.17^{\mathrm{c}}$ & $22.99^{\mathrm{c}}$ & $4.30^{\mathrm{c}}$ \\
\hline L691 & $12.41^{\mathrm{c}}$ & $8.05^{\mathrm{c}}$ & $6.00^{\mathrm{c}}$ & $4.55^{\mathrm{c}}$ & $2.23^{\mathrm{c}}$ & $2.51^{\mathrm{c}}$ \\
\hline L692 & $49.94^{\mathrm{a}}$ & $14.20^{\mathrm{c}}$ & $18.87^{\mathrm{c}}$ & $6.40^{c}$ & $17.65^{\mathrm{c}}$ & $4.58^{\mathrm{c}}$ \\
\hline L693 & $51.57^{\mathrm{a}}$ & $8.98^{c}$ & $10.70^{c}$ & $4.07^{\mathrm{c}}$ & $15.49^{\mathrm{c}}$ & $7.07^{\mathrm{c}}$ \\
\hline L694 & $28.37^{b}$ & $8.16^{\mathrm{c}}$ & $9.09^{\mathrm{c}}$ & $5.88^{\mathrm{c}}$ & $14.94^{\mathrm{c}}$ & $8.75^{\mathrm{c}}$ \\
\hline L695 & $26.46^{c}$ & $10.25^{c}$ & $6.27^{c}$ & $9.26^{\mathrm{c}}$ & $7.74^{c}$ & $5.09^{\mathrm{c}}$ \\
\hline L696 & $35.65^{\mathrm{b}}$ & $6.88^{c}$ & $9.63^{c}$ & $5.74^{\mathrm{c}}$ & $10.68^{\mathrm{c}}$ & $5.80^{\mathrm{c}}$ \\
\hline \multicolumn{7}{|c|}{ Control Genotypes } \\
\hline UENF HS02 & & $6.07^{\mathrm{c}}$ & & L88 & & $63.22^{\text {a }}$ \\
\hline ARZM 13050 & & $48.18^{a}$ & & L51 & & $55.83^{\mathrm{a}}$ \\
\hline Barão de Viçosa & & $17.88^{\mathrm{c}}$ & & & & \\
\hline
\end{tabular}


the specific combining ability among parents is essential to potentiate gains in resistance.

Once the effects of GCA represent the additive action of the alleles, and the SCA results from the dominance deviations provided by specific allele combinations, results suggest the exploration of both additive and nonadditive effects should be prioritized in programs with the goal of increasing the resistance to FER in popcorn, especially to SFER. Therefore, how in breeding programs the hybrid development to improve the grain yield is usually adopted, the choice of lines with smallest FER susceptibility and good GCA is a good option in the hybrids production with phytosanitary grain quality. Similar results were reported by Schwantes et al. (2018).

Regarding GCA, the PARA 172 population generally contributes to the reduction of both IFER and SFER, which corroborates the information from the work of Kurosawa et al. (2017), pointing to have alleles of resistance to FER in this population. In evaluating the combining ability of $\mathrm{P} 1$ line at crosses with lines of three distinct genealogies (BRS Angela, Barão de Viçosa, and Beija-Flor), Schwantes et al. (2017) identified GCA with potential to increase the rates of IFER and SFER. Differently, the results obtained in this study indicate that $\mathrm{P} 1$ line, in general, contributed, even if only moderately, to the reduction of IFER.

Concerning SCA, the L696 x L651, L689 x L70, L686 x L70, and L686 x P1 combinations stood out with the greatest potential contribution to IFER reduction. For SFER reduction, the best combinations were in the L688 x L70, L685 x P1, L694 x PARA 172, and L693 x P1 hybrids. Among the characters IFER and SFER, the SFER reduction is the most desirable in improving the phytosanitary quality of the grains, since lower SFER values indicate less infected grains. In addition, IFER may be further reduced depending on the efficiency of insect control methods capable of causing damage to grains, since they can build entry points for the fungus (Duncan \& Howard, 2010).

Our study shows that the hybrids that showed the best values for SCA were not those that presented the best

Table 4: Estimates of mean squares for incidence and severity of ear rot in different popcorn genotypes (testers, lines, and hybrids); SV: source of variation; GCA: general combining ability; SCA: specific combining ability

\begin{tabular}{|c|c|c|}
\hline \multirow{2}{*}{ SV } & ${ }^{\dagger}$ IFER & SFER \\
\hline & \multicolumn{2}{|c|}{ Mean Squares } \\
\hline Genotypes & $1587.51^{* *}$ & $702.45^{* *}$ \\
\hline GCA Testers & $222.58^{\mathrm{ns}}$ & $230.24^{\mathrm{ns}}$ \\
\hline GCA Inbred Lines & $1726.88^{* *}$ & $1135.69^{* *}$ \\
\hline SCA Hybrids & $1602.43^{* *}$ & $599.66^{* *}$ \\
\hline Error & 131.15 & 101.36 \\
\hline
\end{tabular}

$* * p<0.01 ; \dagger$ Mean Squares for Incidence of Fusarium ear rot (IFER); $\ddagger$ Mean Squares for Severity of Fusarium ear rot (SFER). means for either IFER or SFER. It demonstrates the relevance of the additive effects of the alleles involved in resistance to FER, given that, although the hybrids mentioned above contain the allelic conformations that promoted greater gains per deviation, they did not present higher levels of resistance, probably because of the lower number of favorable alleles to the resistance in parental genotypes.

Additionally, results indicate that identifying lines with better SCA with those most FER resistant lines will enable the produce hybrids with even higher levels of resistance in the future. Thus, in future studies, the identification of lines from other genealogies having better SCA with the L683, L689, L691, and L695 lines should contribute to obtaining hybrids superior to the ones found during this study.

Considering the results, we deduced that the UENF 14 population is a source of alleles of resistance to FER, with the L684, L683, L681, and L695 lines having the best GCA for reduction of the SFER.

Among the testers, the $\mathrm{L} 270$ line provided better data discrimination, while the L651 was the tester that best contributed to the increase in resistance to FER in hybrids. In view of the abovementioned, the L651 line should be indicated as a good parent to be used for topcross crosses. As there were significant differences between means for both IFER and SFER, both characters were used to indicate hybrids more resistant to FER.

For both IFER and SFER, however, the crosses between two parents with higher levels of resistance demonstrated a higher probability of obtaining superior hybrids in resistance, reflecting directly on the GCA of the parents.

In studies involving common maize, while there is disagreement among some authors regarding the possibility of predicting resistance in hybrids based on the performance per se of the lines (Löffler et al., 2011), there are studies defending this possibility as a strategy to increase efficiency in the production of superior maize hybrids (Hung \& Holland, 2012; Netshifhefhe, 2017). Likewise, with the results of this study we suggest that the choice of lines with higher level of resistance to FER for composition of crosses ensures the breeders higher probability of obtaining hybrids superior in resistance.

Additionally, adopting testcrosses throughout the stages of obtaining lines, together with the efficiency of using testcross in the discrimination of lines with better combining ability for resistance to FER, is a strategy that should be encouraged in maize genetic breeding programs. Hence, lines with high capacity to add resistance to FER obtained at the end of the process can be crossed with lines that contribute to agronomic characters of interest to the crop, such as high yield and ability to expand grains. 
Table 5: Estimate of combining abilities of parents and hybrids of popcorn to incidence and severity of ear rot caused by Fusarium (IFER and SFER)

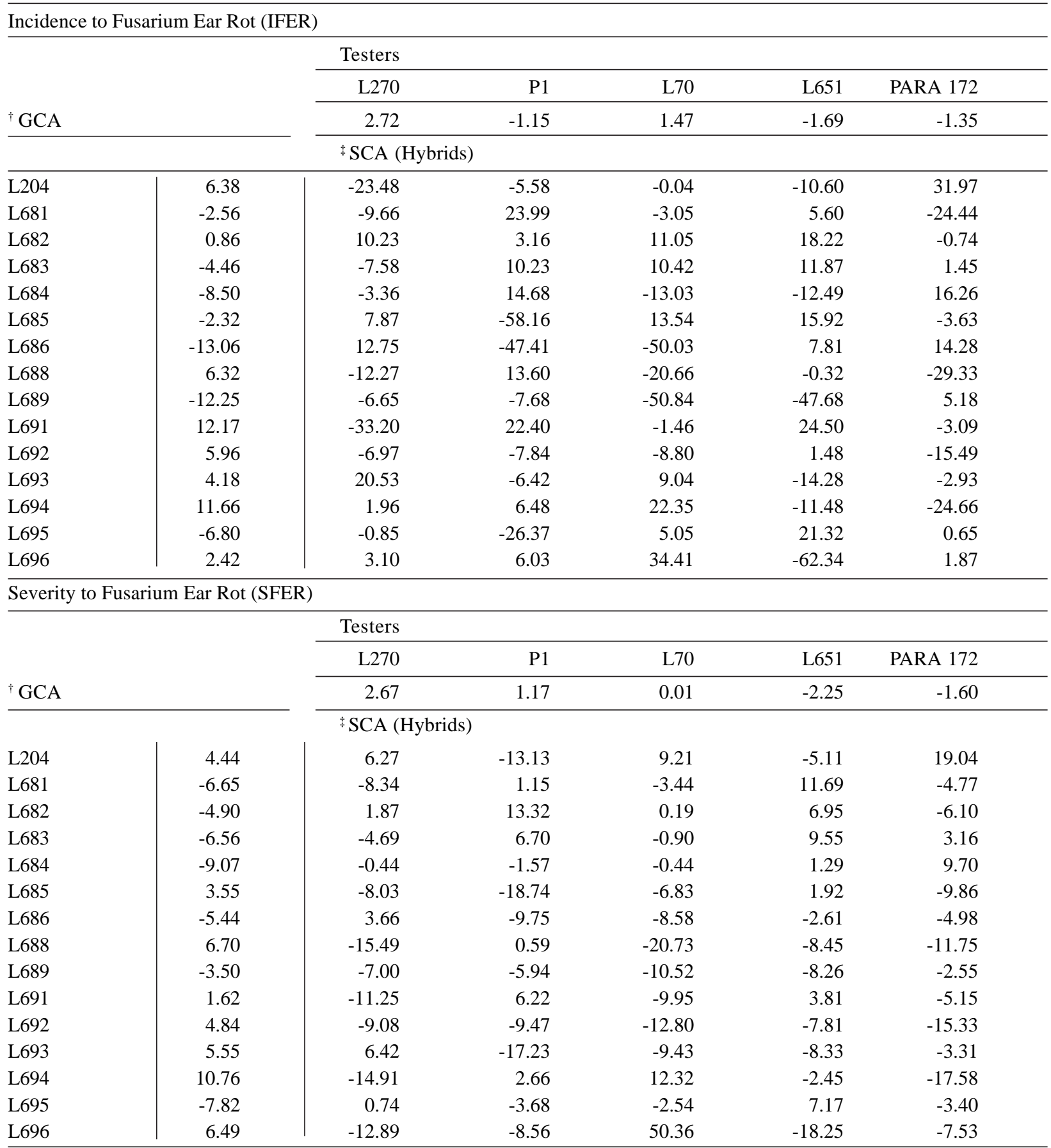

$\dagger$ General Combining Ability (GCA); $\$$ Specific Combining Ability (SCA).

\section{CONCLUSIONS}

Both general combining ability of parents and specific combining ability of hybrid are crucial to obtain superior cultivars in resistance to Fusarium ear rot in popcorn. So, crosses involving inbred lines with favorable alleles to FER resistance and good specific combining ability to reduce the severity of disease are a promising strategy to improve the grain quality in popcorn breeding.

\section{ACKNOWLEDGMENTS}

We thank the Fundação Carlos Chagas Filho de Amparo à Pesquisa do Estado do Rio de Janeiro (FAPERJ) that financed part of the study. This study was financed in part by the Coordenação de Aperfeiçoamento de Pessoal de Nível Superior - Brasil (CAPES) - Finance Code 001. The authors reported no potential conflict of interest. 


\section{REFERENCES}

Amaral Júnior AT, Gonçalves LSA, Freitas Júnior SP, Candido LS, Vittorazzi C, Pena GF, Ribeiro RG, Silva TRC, Pereira MG, Scapim CA, Viana AP \& Carvalho GF (2013) UENF 14: a new popcorn cultivar. Crop Breeding and Applied Biotechnology, 13:218-220.

Brazil (2011) Resolution of the Collegiate Board number 7 of February 18, 2011. Maximum tolerated limits (LMT) for mycotoxins in food. DOU, 22/02/2011, Section 1, p.72.

Cruz CD (2013) GENES - a software package for analysis in experimental statistics and quantitative genetics. Acta Scientiarum, $35: 271-276$

Cruz CD, Carneiro PCS \& Regazzi AJ (2014) Modelos biométricos aplicados ao melhoramento genético. Editora UFV. 668p.

Duncan KE \& Howard RJ (2010) Biology of maize kernel infection by Fusarium verticillioides. Molecular Plant-Microbe Interactions, 23:6-16.

Czembor E, Waœkiewicz A, Piechota U, Puchta M, Czembor JH \& Stepien L (2019) Differences in ear rot resistance and Fusarium verticillioides-produced fumonisin contamination between Polish currently and historically used maize inbred lines. Frontiers in Microbiology, 10:449.

Flett BC, McLaren NW \& Wehner FC (1998) Incidence of ear rot pathogens under alternating corn tillage practices. Plant Disease, $82: 781-784$.

Gabriel LC, Pereira CB, Bavia GP, Coan M, Donel AA, Tessmann DJ \& Scapim CA (2018) Evaluation of resistance of popcorn maize genotypes to fumonisin accumulation and fusarium ear rot. Summa Phytopathologica, 44:286-288.

Galiæ V, Šimiæ D, Franiæ M, Brkiæ A, Jambroviæ A, Brkiæ J \& Ledenèan T (2019) Analysis of Fusarium ear rot and fumonisin contamination in testcrosses of a maize biparental population. Crop Breeding and Applied Biotechnology, 19:40-46.

Geraldi IO \& Miranda Filho JB (1988) Adapted models for the analysis of combining 4 ability of varieties in partial diallel crosses. Brazilian Jounal of Genetics, 11:419-430.

Griffing B (1956) Concept of general and specific combining ability in relation to diallel crossing systems. Australian Journal of Biological Sciences, 9:463-493.

Han S, Utz HF, Liu W, Schrag TA, Stange M, Würschum T, Miedaner T, Bauer E, Schön CC \& Melchinger AE (2016) Choice of models for QTL mapping with multiple families and design of the training set for prediction of Fusarium resistance traits in maize. Theoretical and Applied Genetics, 129:431-444.

Horne DW, Eller MS \& Holland JB (2016) Responses to recurrent index selection for reduced Fusarium ear rot and lodging and for increased yield in maize. Crop Science, 56:85-94.

Hung HY \& Holland JB (2012) Diallel analysis of resistance to Fusarium ear rot and fumonisin contamination in maize. Crop Science, 52:2173-2181.

International Maize and Wheat Improvement Center - CIMMYT (1985) Managing 17 trials and reporting data for CIMMYT's international maize testing program. Available at: https:// repository.cimmyt.org/xmlui/handle/10883/697?locale19\%20attribute=e. Accessed on: December $9^{\text {th }}, 2020$.

International Maize and Wheat Improvement Center - CIMMYT (2019) CIMMYT-Maize Germplasm Bank 1.10.4. Available at: https://doi.org/10.18730/H1C4V. Accessed on: December 9 $9^{\text {th }}, 2020$.

Jindal KK, Zhu S, Tenuta AU, Javed N, Daayf F \& Reid LR (2019) Maize inbreds for multiple resistance breeding against major foliar, ear and stalk rot diseases. Maydica, 64:22.
Kurosawa RNF, Amaral Junior AT, Vivas JMS, Guimarães AG, Miranda SB, Dias VM \& Scapim CA (2017) Potential of popcorn germplasm as a source of resistance to ear rot. Bragantia, 76:378385 .

Lanubile A, Maschietto V, Borrelli VM, Stagnati L, Logrieco AF \& Marocco A (2017) Molecular basis of resistance to Fusarium ear rot in maize. Frontiers in Plant Science, 8:1774.

Li YG, Jiang D, Xu LK, Zhang SQ, Ji PS, Pan HY, Jiang BW \& Shen ZB (2019) Evaluation of diversity and resistance of maize varieties to Fusarium spp. causing ear rot in maize under conditions of natural infection. Czech Journal of Genetics and Plant Breeding, 55:131-137.

Löffler M, Kessel B, Ouzunova M \& Miedaner T (2011) Covariation between line and testcross performance for reduced mycotoxin concentrations in European maize after silk channel inoculation of two Fusarium species. Theoretical and Applied Genetics, 122:925-934.

Logrieco A, Mulè G, Moretti A \& Bottalico A (2002) Toxigenic Fusarium species and mycotoxins associated with maize ear rot in Europe. European Journal of Plant Pathology, 108:597-609.

Mabuza LM, Van Rensburg BJ, Flett BC \& Rose LJ (2018) Accumulation of toxigenic Fusarium species and Stenocarpella maydis in maize grain grown under different cropping systems. European Journal of Plant Pathology, 152:297-308.

Medina A, Akbar A, Baazeem A, Rodriguez A \& Magan N (2017) Climate change, food security and mycotoxins: do we know enough? Fungal Biology Reviews, 31:143-154.

Miranda Filho JB (2014) Testadores e Dialelos. In: De Lima RO \& Borém A (Ed.) Melhoramento de Milho. Viçosa, Editora UFV. p.130-158.

Missmer SA, Suarez L, Felkner M, Wang E, Merrill AHJ, Rothman KJ \& Hendricks KA (2006) Exposure to fumonisins and the occurrence of neural tube defects along the Texas-Mexico Border. Environmental Health Perspect, 114:237-241.

Nerbass FR, Casa RT, Kuhnem PR, Bogo A, Sangoi L, Fingstag MD, Vieira Junior JAL \& Stoltz JC (2016) Evaluation of Fusarium graminearum inoculation methods in maize ears and hybrid reaction to Gibberella ear rot under southern Brazilian environmental conditions. European Journal of Plant Pathology, 144:45-53.

Netshifhefhe NEI (2017) Evaluation of maize breeding populations for resistance to Fusarium verticillioides and fumonisin contamination. Dissertação de Mestrado. Stellenbosch University, Stellenbosch. 116p.

Pacheco CAP, Gama EEG, Parentoni SN, Santos MX, Lopes MA, Ferreira ADS \& Feldman RO (2001) BRS Angela: variedade de milho pipoca. Brasília, Embrapa/Centro Nacional de Milho e Sorgo. 4p. (Boletim Técnico, 27).

Pereira GS, Pinho RGV, Pinho EVRV, Pires LPM, Bernardo Junior LAY, Pereira JLA \& Melo MP (2017) Selection of maize inbred lines and gene expression for resistance to ear rot. Genetics and Molecular Research, 16:1-21.

Robertson LA, Kleinschmidt CD, White DG, Payne GA, Maragos CM \& Holland JB (2006) Heritabilities and correlation of Fusarium ear rot resistance and fumonisin contamination resistance in two maize populations. Crop Science, 46:353361.

Ross PF, Nelson PE, Richard JL, Osweiler GD, Rice LG, Plattner RD \& Wilson TM (1990) Production of fumonisins by Fusarium moniliforme and F. proliferatum associated with equine leukoencephalomalacia and a pulmonary edema syndrome in swine. Applied and Environmental Microbiology, 56:32253226.

Rev. Ceres, Viçosa, v. 68, n.1, p. 061-070, jan/feb, 2021 
Santiago R, Cao A, Malvar RA \& Butrôn A (2020) Genomics of maize resistance to Fusarium ear rot and fumonisin contamination. Toxins, 12:431.

Schwantes IA, Amaral Júnior AT, Gerhardt IFS, Vivas M, Silva FHDL \& Kamphorst SH (2017) Diallel analysis of resistance to Fusarium ear rot in Brazilian popcorn genotypes. Tropical Plant Pathology, 42:70-75.

Schwantes IA, Amaral Júnior AT, Vivas M, Almeida Filho JED, Kamphorst SH, Guimarães AG \& Khan S (2018) Inheritance of resistance to Fusarium ear rot in popcorn. Crop Breeding and Applied Biotechnology, 18:81-88.
Solalinde JMQ, Scapim CA, Vieira RA, Amaral Júnior AT, Vivas M, Pinto RJB, Mora F \& Viana AP (2014) Performance of populations in South American Avatí Pichingá popcorn maize using diallel analysis. Australian Journal of Crop Science, 8:16321638 .

Sprague GF \& Tatum LA (1942) General vs. specific combining ability in single crosses of corn. Agronomy Journal, 34:923932 . 